\title{
Rhetoric and the Rule of Law: an author's day with Neil MacCormick
}

\begin{abstract}
Introduction *
George Pavlakos

\section{Research Chair in Globalisation and Legal Theory, University of Antwerp, Faculty of} Laws; Professor of Globalisation and Legal Theory, University of Glasgow, School of Law

$\mathrm{M}$ acCormick's legal theory has consistently represented the most serious effort in the common law world to defend the concept of legal reasoning as the key concept in any effort to understand legal phenomena. As such it is a theory that resists classification in terms of the simplistic distinction between positivism and non-positivism. However, when one compares the early with the late phase of his thought, one realises that MacCormick has come to endorse more of the key ideas shared by non-positivist lawyers. That said, he rarely conducts his analysis in the vocabulary of the positivism-non-positivism debate; far from it, in Rhetoric and the Rule of Law (RRL) ${ }^{1}$ the author underpins his non-positivist turn with important insights on logic, deduction and analogy, and the function of statute and precedent in legal reasoning. In the brief introduction that follows, I shall try to draw some connections between the two phases of MacCormick's work as well as to highlight some of the main points our speakers will be raising today.

Legal Reasoning and Legal Theory (LRLT), ${ }^{2}$ the book that established MacCormick as the leading legal theorist of his day, represents an effort to break away from the static view of law that (Hartian) positivism is infected with. Pertinent to positivism is the view that law consists of determinate propositions (rules) which demarcate the domain of the legal. When these rules run out, so does law. What makes this view static is the emphasis on a test of recognition which purports to identify exhaustively the rules that make up a legal system. In disregarding the application of rules, this model fails to account for whatever belongs to the legal realm, albeit not forming part of the content of rules. In contrast to the static view, MacCormick attempted to put rules in action, by focusing on the domain of persuasive reasons which underpin the application of rules. Such reasons comprise consequentialist

\footnotetext{
* This introduction and the three papers following it were originally presented at a symposium at the School of Law, Queen's University Belfast on 28 April 2006. The fourth paper is a response from Sir Neil MacCormick.

1 N MacCormick, Rhetoric and the Rule of Law, Oxford: OUP, 2005.

2 N MacCormick, Legal Reasoning and Legal Theory, Oxford: Clarendon, 1978.
} 
arguments as well as arguments from principle and other evaluative considerations which feature alongside the legal syllogism each time lawyers and judges reach their normative conclusions. All those different types of persuasive reasons fill the gaps the static picture of positivism leaves in our understanding of the law.

Already in that first book on legal reasoning we discern the tension between the antithetical concepts that feature in the title of the latest one: "rule of law" stands for the static aspect of rules, while "rhetoric" purports to capture the domain of persuasive argument. The two aspects are reconciled as two distinct, albeit interconnected, levels of legal reasoning: rules work through deduction and syllogistic reasoning, while persuasive argument works in a less formalised way, yet one that is capable of rational persuasion, along the lines of Perelman's conception of Rhetoric.

When those ideas were advanced in 1978 they were offered as a defence of positivism vis-à-vis what had already started to emerge as Dworkin's interpretivist challenge. While Dworkin exploited the gap between rules and persuasive argument (most notably, putting his emphasis on principles of political philosophy) with a view to showing that the static model breaks down (and, in a further step, to arguing that, if we want to uphold the ideal of the rule of law we had better conceive of it in terms of principles), MacCormick, in a more sombre tone, defended the possibility of co-existence of rules and principles (evaluations) as two aspects of the same process of legal reasoning, hence the view that positivism was not fundamentally flawed but merely elliptical.

In this context, and contrary to what John Gardner has argued in a recent book review in the Times Literary Supplement, MacCormick's use of the terms "rhetoric" and "rule of law" in the title of his sequel (RRL) is not merely fanciful (also, I should add, the further accusation by the same reviewer that rhetoric hardly features in the book is misplaced, unless one has not understood the project McCormick has embarked on since 1978). RRL revisits the tension between the static and the dynamic aspects of legal reasoning in the light of a series of prominent criticisms that took shape in the 28 years after the appearance of LRLT. Given that critics have mainly insisted on the precariousness of MacCormick's reconciliatory project, MacCormick's recent replies illustrate an effort to take the edge out of the tension with a view to demonstrating the viability of his earlier project. How much do these replies deviate from earlier views and to what extent does the later work constitute a revision of the earlier one?

The most important revision or addition RRL undertakes is in arguing that what belongs to the domain of persuasion (principles, evaluations) admits of universal justification to a much larger extent than he had admitted in his early work. Along these lines persuasive reasons may amount to universal justifications, bridging thus the gap between a static and a dynamic account of law. Three key considerations may be identified in this context.

First, MacCormick arrives at a more expansive understanding of what universalisation may comprise by moving away from a Humean explication of value and accepting that it is possible to assess the universality of evaluative propositions independently of the psychology of (particular) judging subjects. As a result, legal argument may be underpinned by evaluative reasons without risking a preposterous amount of indeterminacy, such that would endanger the ideal of the rule of law. A useful illustration of this point is put forward by Stefano Bertea in his comment on RRL. ${ }^{3}$ In it Bertea argues that RRL puts forward something like an "argumentation thesis" or the view that legal reasoning is a constitutive element of the concept of law. Resting on this diagnosis Bertea suggests that the

3 pp. 5-20, this issue. 
argumentative character of law necessitates the import of evaluative (moral) reasons into any account of law for, he assumes, such arguments are rationally justifiable (universalisable).

Second, in his belief that universal justifications may pertain to evaluative arguments, MacCormick departs from a strict deductive model: as it were, it is not deductive reasoning which performs the task of universalisation but, instead, reference to the particular aspects of a case. Through this link, normative claims become universal because of the characteristics of a case and not any abstract formula akin to the positivist understanding of rules (or, even, any a-contextual values postulated by Dworkin). Thus, albeit valid in a universal manner, principles are not valid in an a priori manner. They can still be revised and amended in the light of new data. Prominent in this respect is the case of the conjoined twins: this is an instance of a universally valid judgment, albeit valid for what may turn out to be a very limited number of cases. Giovanni Sartor's detailed contribution "Syllogism and defeasibility: a comment on Neil MacCormick's Rhetoric and the Rule of Law"4 affirms MacCormick's belief in the possibility of justification of evaluative arguments. However, Sartor suggests that one need not abandon the domain of logic in order to achieve this. In fact to do so would give away a narrow understanding of the nature of logic as well as of the division of labour between logic and rhetoric. Conversely, Sartor suggests that many of the tasks delegated to rhetoric may be carried out by syllogistic reasoning, once we consider a number of modern views on logic and the nature of syllogistic reasoning.

Third, as a result of MacCormick's particularist explication of justification, analogical reasoning remains prominent in his revised theoretical edifice. Analogy and the use of precedent demonstrate in the best manner the new objectivism MacCormick advocates: a universality that is based on the particular features of a judgment rather than any a priori grounds (positivism) or a complete negation of the possibility to universalise at all (psychologism). Leonor Moral Soriano, in her essay "Precedents: reasoning by rules and reasoning by principles", 5 sets out to demonstrate the prominence of analogical reasoning in MacCormick's recent work by emphasising the argumentative character of legal precedents and, subsequently, taking stock with the common functions precedents perform in the common and civil law systems.

In conclusion, I view RRL as an effort to close the gap between two simplistic views of legal reasoning: the view that fixed rules can account for certain conclusions and the contrapuntal view that there are evaluations which are fixed independently of legal systems. The early MacCormick remained to a larger extent a captive of this dilemma, because his Humeanism gave rise to the dichotomy: either, a priori, strong objectivism or subjectivity of values; this was forcing him to retain a limited sphere of certainty, within rules, while rejecting the possibility of universal justification in the realm of evaluations. In the light of the new arguments put forward in RRL the dilemma need not stand: evaluations can be included within legal reasoning, for it is possible to assess them without evoking a preposterous amount of objectivity. This is best illustrated in the particularist structure of analogical reasoning. Most notably, the representative of universalist legal reasoning par excellence, Robert Alexy, has recently admitted that beyond deductive reasoning (rules) and balancing (principles) there is a third kind of legal reasoning, analogical reasoning. 
